\title{
Antibody Isotype Responses in Balb/c Mice Immunized with the Cytoplasmic Repetitive Antigen and Flagellar Repetitive Antigen of Trypanosoma cruzi
}

\author{
Valéria RA Pereira, Virginia Maria B Lorena, Alinne Fernanda A Verçosa, \\ Edmilson D Silva**, Antonio GP Ferreira**, Ulisses R Montarroyos, Ana P Galvão Silva*, \\ Yara M Gomes ${ }^{++}$
}

Departamento de Imunologia and Departamento de Saúde Coletiva, Centro de Pesquisas Aggeu Magalhães-Fiocruz, Av. Moraes Rego s/n, Cidade Universitária, 50670-420 Recife, PE, Brasil *Departamento de Patologia, Universidade Federal de Pernambuco, Recife, PE, Brasil **Departamento de Reativos, Biomanguinhos-Fiocruz, Rio de Janeiro, RJ, Brasil

In the present report we analyzed the levels of $\operatorname{IgG1} \operatorname{IgG2a}$, IgG2b and IgG3 isotypes from Balb/c mice immunized with cytoplasmic repetitive antigen (CRA), and flagelar repetitive antigen (FRA) of Trypanosoma cruzi. The immunization was done by subcutaneous route three times (20 days apart) and the analysis was performed 14 days after each treatment. CRA-immunized mice produced high levels of all IgG isotypes, mainly IgG3 and IgG1. FRAimmunization elicited only high levels of IgG1.

Key words: Trypanosoma cruzi - recombinant antigens - immunization - isotypes

Trypanosoma cruzi infection in both humans and mice develop a strong and heterogeneous humoral immune response as shown by circulating specific antibodies. These antibodies are involved in resistance to parasite and studies on the immunoglobulins isotypes present in host surviving acute infection has indicated the importance of these responses (Brodskyn et al. 1989, Bouhdidi et al. 1994). In infected mice, the major anti-parasite response consist of the $\operatorname{IgG} 1$ and $\operatorname{IgG} 2$ isotypes as demonstrated by indirect immunofluorescence (Araújo et al. 1984), western blot (Rowland et al. 1992), lytic activity (Krettli et al. 1979), clearance of T. cruzi bloodstream trypomastigotes (Brodskyn et al. 1989) and passive transfer protection (Takehara et al. 1981).

CRA (cytoplasmic repetitive antigen) and FRA (flagellar repetitive antigen) recombinant antigens (Rec$\mathrm{Ag}$ ) of $T$. cruzi have been used, successfully in serodiagnosis of Chagas disease (Krieger et al. 1992, Gomes et al. 2001). FRA is located in the flagellum of the epimastigote and trypomastigote forms of T. cruzi and displays a 68-amino acid repeat, while CRA is distributed throughout the cytoplasm of epimastigote and amastigote forms and has a 14-amino acid repeat (Lafaille et al. 1989).

This work was financed by Bio-Manguinhos-Fiocruz (grant CC 004/2000) and CNPq. VMB de Lorena and AFA Verçosa are fellows $\mathrm{CNPq}$ (Pibic/Fiocruz) and VRA Pereira is a doctoral fellow CNPq.

+Corresponding author. Fax: +55-81-3453.2449. E-mail: yara@cpqam.fiocruz.br

Received 24 April 2003

Accepted 25 July 2003
The response of chagasic patients to these antigens (Krieger et al. 1992, Gomes et al. 2001) led us to investigate their immunologial response in experimental animals.

In the present communication we analyzed the isotype profiles of immunoglobulins in uninfected mice exposed to CRA and FRA Rec-Ag of T. cruzi, in order to further use them in immunotherapy assays.

Male Balb/c mice (6 to 8 week-old) were used following the guidelines of the Ethical Committee to use of Experimental Animals from the Oswaldo Cruz Foundation (Ministry of Health, Brazil).

CRA and FRA Rec-Ag were obtained from BioManguinhos-Fiocruz according to Krieger et al. (1992) and used as antigens. Groups of 6 to 8 -week-old male Balb/c mice were injected by subcutaneous route with three doses of purified Rec-Ag CRA $(20 \mu \mathrm{g})$, and FRA $(12 \mu \mathrm{g})$ at 20 days of intervals. The first dose was emulsified in complete Freund's adjuvant and the following in incomplete Freund's adjuvant. The same schedule was used for control mice that received only adjuvant.

Before and 14 days after each dose, sera from individual mice were tested for IgG1, IgG2a, IgG2b, and IgG3 isotypes by ELISA. Briefly, microtiter plates (Nunc-Immuno Plates, MaxiSorp, 96 wells, Nalgen Nunc International Corporation) were coated with $1 \mu \mathrm{g} / \mathrm{ml}$ of CRA or FRA (100 $\mu 1 /$ well) diluted in $0.05 \mathrm{M} \mathrm{Na}_{2} \mathrm{CO}_{3}$ buffer, $\mathrm{pH} 9.6$ and incubated overnight at $4{ }^{\circ} \mathrm{C}$. The plates were blocked with PBS-Tween $20(0.05 \%)$ (PBS-Tw) containing 5\% fat free milk (Nestlé), prior to incubation with $100 \mu \mathrm{l}$ of sera diluted (1:100) in PBS-Tw (overnight, $4^{\circ} \mathrm{C}$ ). The bound antibodies were detected by incubation with horseradish peroxidaseconjugated isotype specific rabbit anti-mouse immunoglobulin (Caltag). The reaction was detected by the addition of orthophenyldiamine-OPD plus $\mathrm{H}_{2} \mathrm{O}_{2}$ and stopped with $\mathrm{H}_{2} \mathrm{SO}_{4} 2,5 \mathrm{~N}$. Quantification of the reaction 
was determined by optical density using an automated ELISA reader at $490 \mathrm{~nm}$ (Bio-Rad 3550). Statistical analysis was performed using the Mann-Whitney $U$-test for nonparametric distributions.

The kinetics of $T$. cruzi specific antibody levels for each IgG isotype are shown in the Figs 1 and 2. We found a marked difference in the pattern of antibody response elicited by immunization with CRA Rec-Ag when compared to the FRA Rec-Ag. The levels of all IgG isotypes in CRAimmunized mice were significantly increased $(p<0.05)$ after the 2 nd and 3 rd immunizations when compared to the values observed in control mice and preimmune sera. Predominant levels of IgG3 and IgG1 characterized CRA immunization. In contrast, immunization with FRA elicited an antibody response mediated by $\operatorname{IgG} 1(\mathrm{p}<0.05)$. The isotypes $\operatorname{IgG} 2 \mathrm{a}, \operatorname{IgG} 2 \mathrm{~b}$, and $\operatorname{IgG} 3$ were not detectable in the sera of FRA-immunized mice.

The immune response against $T$. cruzi experimental infection involves many factors. This parasite in the extracellular phase is susceptible for the destruction by immunological reactions which involve humoral factors
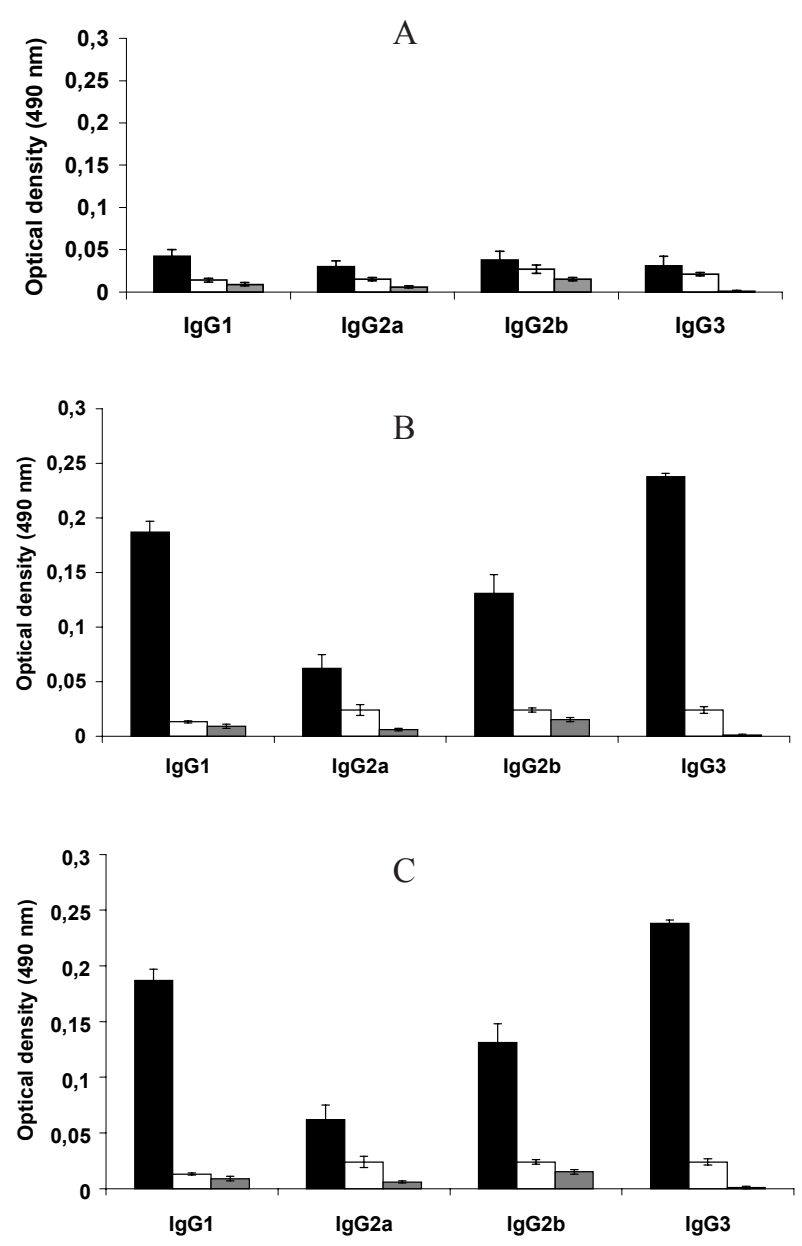

Fig. 1: kinetics of immunoglobulins $\mathrm{G}$ isotypes in mice immunized with cytoplasmic repetitive antigen of Trypanosoma cruzi. ELISAs were done 14 days after each dose of immunization. A: first dose; B: second dose; C: third dose. Bars respresent immunized mice ( $\square$ ), control mice ( $\square$ ) and preimmune sera $(\square)$, respectively. The results are expressed as the average of five mice \pm SD.
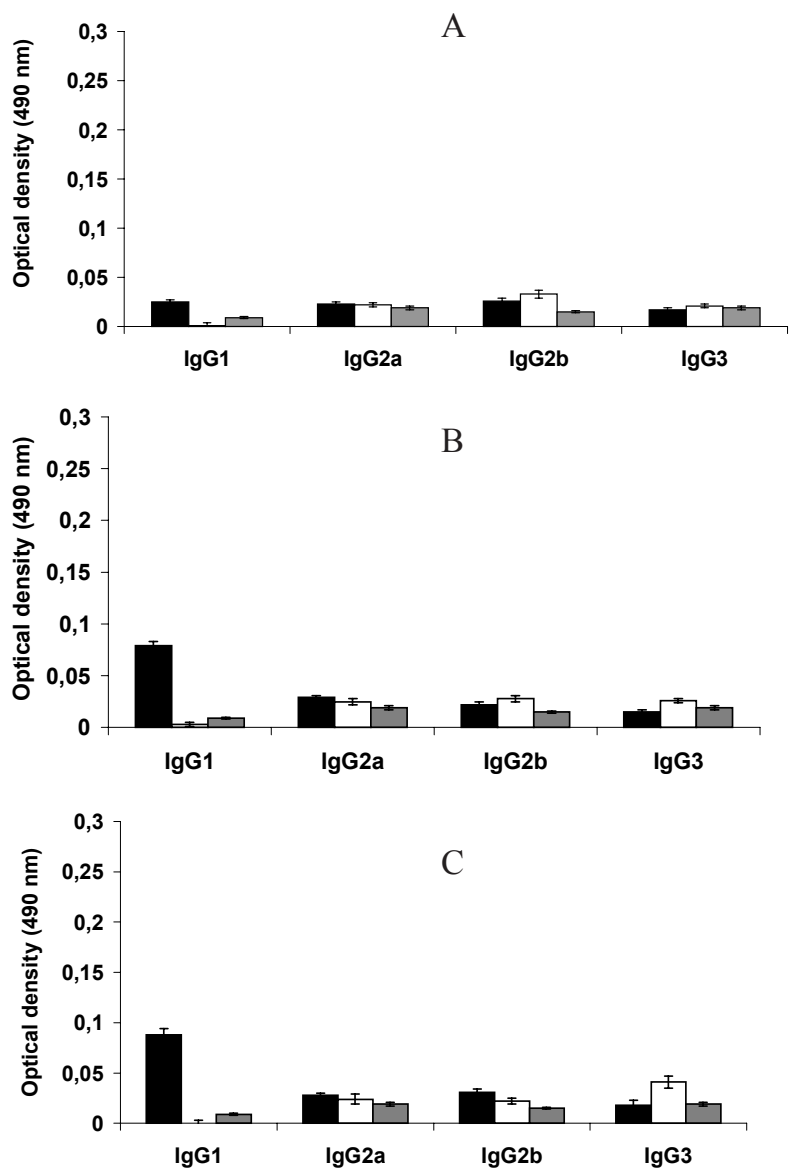

Fig. 2: kinetics of immunoglobulins $\mathrm{G}$ isotypes in mice immunized with flagellar repetitive antigen of Trypanosoma cruzi. ELISAs were done 14 days after each dose of immunization. A: first dose; B: second dose; C: third dose. Bars respresent immunized mice ( $\mathbf{\square})$, control mice $(\square)$ and preimmune sera $(\square)$, respectively. The results are expressed as the average of five mice \pm SD.

or combined action of specifics antibodies and its receptors in leukocytes surface (Kierszenbaum \& Lima 1983). Krettli and Brener (1976) have demonstrated that partial protection could be obtained by the transference of antibodies anti-tripomastigote proceeding from infected mice. Serum of animals infected with $\mathrm{Y}$ and Colombian strains have been capable to confer partial protection against $Y$ strain, once the pre-incubation of the parasites with immune sera decreased the infectivity of tripomastigote. The ability of the antibodies in conferring protection depends on the class and subclass of immunoglobulin to which they belong, and only the transference of $\operatorname{IgG} 2 \mathrm{a}$ and $\mathrm{IgG} 2 \mathrm{~b}$ antibodies could protect the animals, decreasing the parasitemia and mortality rates (Takehara et al. 1981, Brener \& Krettli 1990). The detection of the different immunoglobulin isotypes induced by CRA demonstrate that this antigen is able to induce humoral immune response. Although this antigen was more potent to induce $\mathrm{IgG1}$ and $\mathrm{IgG} 3$ isotypes, it also increased $\operatorname{IgG} 2 \mathrm{a}$ and IgG2b levels. On the other hand, FRA was more potent 
to induce only $\operatorname{IgG} 1$ isotype. Previous studies have demonstrated that IgG2a, IgG2b and IgG1 are important isotypes involved in the elimination of blood forms of the parasite (Brodskyn et al. 1989). However, our results also suggest the possibility of $\mathrm{IgG} 3$ having a significant role in protection against infection. Thus, the antibodies detected in CRA and FRA-immunized mice could help to control of the parasitemia in a later infection. In conclusion, preliminary evidence was provided that both CRA and FRA Rec-Ag activate immune mechanisms involved in parasite elimination. These approaches are currently being evaluated in immunized and challenged mice.

\section{ACKNOWLEDGEMENTS}

To Dr Eridan Coutinho for critical reading of the manuscript. To Dr Samuel Goldenberg and Dr Marco Krieger for helpful discussion. To Mineo Nakazawa for their excelent technical assistance.

\section{REFERENCES}

Araújo FG, Helman B, Tighe L 1984. Antigens os Trypanosoma cruzi detected by different classses and subclasses of antibodies. Trans R Soc Trop Med Hyg 78: 672-677.

Bouhdidi AE, Truyens C, Rivera MT, Bazin H, Carlier Y 1994. Trypanosoma cruzi infection in mice induces a polysotypic hypergammaglobulinaemia and parasite-specific response involving high IgG2a concentrations and highly avid IgG1 antibodies. Parasite Immunol 16: 69-76.

Brenner Z, Krettli AU 1990. Immunology of Chagas disease. In DJ Wyler, Modern Parasite Biology-Celullar, Immunological, and Molecular Aspects, Freeman Company, New York, p. 247-261.

Brodskyn CI, Silva AMM, Takehara HA, Mota I 1989. IgG subclasses responsible for immune clearance in mice infected with Trypanosoma cruzi. Immunol Cell Biol 67: 343-348.

Gomes YM, Pereira VRA, Nakazawa M, Rosa DS, Fereira AGP, Silva ED, Krieger M, Goldenberg S 2001. Serodiagnosis of chronic Chagas' disease by using EIE-RecombinantChagas-Biomanguinhos. Mem Inst Oswaldo Cruz 96: 497501.

Kierszenbaum F, Lima MF 1983. Susceptibility of insect-borne, metacyclic forms of $T$. cruzi to antibody-mediated mechanisms of destruction. Am J Trop Med Hyg 32: 12361241.

Krettli AU, Brener Z 1976. Protective effects of specific antibodies in Trypanosoma cruzi infection. J Immunol 116: 755-760.

Krettli AU, Weisz-Corrington P, Nussenzweig RS 1979. Membrane-bound antibodies to bloodstream Trypanosoma cruzi in mice: strain differences in susceptibility to complement-mediated lysis. Clin Exp Immunol 37: 416-423.

Krieger MA, Almeida E, Oelemann W, Lafaille JJ, Pereira JB, Krieger MA, Carvalho MR, Goldenberg S 1992. Use of recombinant antigens for the accurate immunodiagnosis of Chagas' disease. Am J Trop Med Hyg 46: 427-434.

Lafaille JJ, Linss J, Krieger MA, Souto-Padron T, de Souza W, Goldenberg S 1989. Structure and expression of two Trypanosoma cruzi genes encoding antigenic proteins bearing repetitive epitopes. Mol Biochem Parasitol 35: 127-136.

Rowland EC, Mikhail KS, McCormick TS 1992. Isotype determination of anti-Trypanosoma cruzi antibody in murine Chagas' disease. J Parasitol 78: 557-561.

Takehara HA, Perini A, Silva MH, Mota I 1981. Trypanosoma cruzi: role of different antibody classes in protection against infection in the mouse. Exp Parasitol 52: 137-146. 